doi: 10.37321/UJMH.2018.02-03

() Ю. И. Заседа, Р. И. Соломенный, Ф. Б. Шихалиев, 2018

УДК 615.038:616.65-002-022

Ю. И. Заседа, Р. И. Соломенный, Ф.Б. Шихалиев

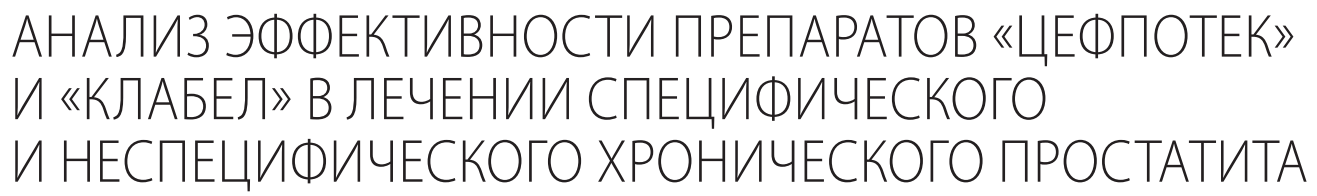

Клиника «Мужское Здоровье» г. Киев, Украина

\author{
Yu. I. Zasieda, R. I. Solomianyi, F. B. Shykhaliiev
}

\title{
THE ANALYSIS OF EFFICACY OF “CEFPOTEC" AND “CLABEL" PREPARATIONS IN TREATMENT OF SPECIFIC AND NONSPECIFIC PROSTATITIS
}

"Man's health" clinic, Kyiv, Ukraine

Резюме Ц Цель исследования: установление эффрективности препаратов Цефпотек (цефподоксим) и Клабел (кларитромичин) в терапии хронического воспаления предстательной железы в стадии выраженного обострения, вызванного неспецифическими инфекционными агентами и инфекциями группы тусорlasma u chlamydia.

Материалы и методы. Исследование проведено в проспективном дизайне на параллельных группах. Контингент исследования составили 60 пачиентов ТОВ «Клиника «Мужское Здоровье», страдающих хроническим простатитом, в стадии выраженного обострения. В качестве методов исследования были использованы: сонографическое исследование предстательной железы, бактериологический посев эякулята, анализ секрета простаты и ПЦР-диагностика специфических инфекций.

Результаты исследования. Проведен дифференцированный курс этиотропной терапии. При неспецифическом простатите: пероральное назначения препарата «Цефпотек» по 1 таблетке (200 mg) 2 раза в сутки в рамках курса продолжительностью 14 суток с возможностью продления курса до 28 суток. При специфическом простатите: пероральное назначения препарата «Клабел» (кларитромицин) по 1 таблетке (500 mg) 2 раза в сутки в рамках курса продолжительностью 14 суток.

Выводы. При терапии хронического воспаления предстательной железы в стадии выраженного обострения, вызванного неспецифическими инфекционными агентами с использованием перорального назначения препарата «Цефпотек», полная эффективность была достигнута в диапазоне от $83,3 \%$ до 96,6\%. При терапии хронического воспаления предстательной железы в стадии выраженного обострения, вызванного инфекционными агентами группы тусорlasma и chlamydia с использованием перорального назначения препарата «Клабел», полная эффрективность была достигнута в диапазоне от 80,0\% до 86,6\% наблюдений (вне зависимости от особенностей сочетаний специфической микст-инфекции).

Ключевые слова: простатит, микст-инфекция, антибиотикотерапия, микоплазма, хламидия.

Актуальность. Воспалительные заболевания предстательной железы и урогенитального тракта являются наиболее распространенной причиной обращения пациентов за специализированной урологической помощью. Несмотря на все возрастающий мировой опыт клинических интервенций и исследований, направленных на оптимизацию стратегий терапии патологии данного спектра, эффективность лечения демонстрирует значительные индивидуальные флуктуации, объясняющиеся общими для всего спектра инфекционной патологии факторами. К таковым относятся, прежде всего, микст-инфекции с формированием агонистических отношений между возбудителями и искус- 
ственный отбор инфекционных агентов резистентных к рутинным фармакотерапевтическим средствам $[2,3,6,7,8]$.

Указанные факторы приводят к значительным затруднениям в проведении краткосрочных амбулаторных курсов терапии воспалительных заболеваний урогенитального тракта, в рамках которых не предусматривается комплексное исследование и установление биологических характеристик возбудителя, что создает проблему уже организационного характера - невозможности эффективной терапии данного класса пациентов в рамках первичного звена медицинской помощи $[6,7,8]$.

С другой стороны, В настоящий момент большое распространение получили неспецифические формы воспалительных заболеваний урогенитального тракта, развивающиеся вследствие присоединения инфекционных агентов, часто - условно-патогенного характера к уже существующим хроническим патологическим состояниям, что относится, прежде всего, к патологии предстательной железы, частота которой в популяции мужчин репродуктивного возраста достигает, по данным различных эпидемиологических исследований, 6-10\%. Дополнительно подобные случаи могут отягощаться активацией супрессированных микробных внутриклеточных агентов, традиционно рассматриваемых в контексте заболеваний, передающихся половым путем - mycoplasma hominis, mycoplasma genitalium, ureaplasma urealyticum и chlamydia trachomatis, а также рутинных грибковых агентов, в частности candida spp $[1,3,4,5,8]$.

Микст-инфекции, формирующиеся В данном модусе, несмотря на ординарный характер каждого из инфекционных агентов, их достаточную изученность и высокую частоту встречаемости, составляют значительные затруднения в терапии, прежде всего в силу сложности подбора подходящей терапии, которые были бы доступны вне специализированных центров стационарного лечения.

Цель исследования: установление эффективности препаратов Цефпотек (цефподоксим) и Клабел (кларитромицин) в терапии хронического воспаления предстательной железы в стадии выраженного обострения, вызванного неспецифическими инфекционными агентами и инфекциями группы mycoplasma и chlamydia.

Дизайн исследования. Исследование проведено в проспективном дизайне на параллельных группах. Контингент исследования составили 60 пациентов ТОВ «Клиника «Мужское Здоровье», страдающих хроническим простатитом, в стадии выраженного обострения. Контингент сформирован на основании установления инфекционного агента и его биологических характеристик и разделен на 2 группы:

- первая группа (Г1): 30 пациентов страдающих хроническим простатитом неспецифической этиологии в стадии выраженного обострения с доказанной чувствительностью к цефподоксиму;

- вторая группа (Г2): 30 пациентов страдающих хроническим простатитом ассоциированным с инфекционными агентами группы mycoplasma и chlamydia в стадии выраженного обострения с доказанной чувствительностью к кларитромицину.

\section{Исследование проведено в 3 этапа:}

1) диагностический - включал набор пациентов и проведение инициального комплекса лабораторных исследований, направленных на подтверждение диагноза и установление биологических характеристик возбудителя, в том числе и антибиотикорезистентности, на основании чего было проведено распределение пациентов на группы исследования;

2) терапевтический - включал проведение курса лечения пациентов в группах исследования с целевым использованием препаратов «Цефпотек» в Г1 и «Клабел» в Г2;

3) обсервационный - включал оценку эффективности проведенного курса терапии на основании клинических данных и повторного цикла лабораторных исследований. 
Результаты исследования. На первом этапе был проведен комплекс лабораторных исследований, который включал:

- сонографическое исследование предстательной железы: с целью оценки степени и характера патологии предстательной железы, исключения нецелевых форм патологии и подтверждения клинического диагноза лежащего в основе формирования контингента исследования;

- анализ секрета простаты для установления наличия маркеров воспаления.

- бактериальный посев эякулята на условно-патогенную микрофлору и
Candida spp., с определением антибиотикочувствительности, проведенный с целью формирования групп исследования;

- ПЦР-диагностика основных возбудителей заболеваний, передающихся половым путём, в том числе инфекционных агентов mycoplasma genitalium, mycoplasma hominis, ureaplasma urealyticum, и chlamydia trachomatis c целью исключения нецелевой патологии и формирования групп исследования.

По результатам этапа были сформированы группы исследования (табл. 1.)

Таблица 1

Характер инфекционных агентов в группах исследования

\begin{tabular}{|l|c|c|}
\hline \multicolumn{1}{|c|}{ Критерий } & $\begin{array}{c}\text { Г1 } \\
(\mathbf{N = 3 0 )}\end{array}$ & $\begin{array}{c}\text { Г2 } \\
(\mathbf{N = 3 0 )}\end{array}$ \\
\hline Антибиотикочувствительность & цефподоксим & кларитромицин \\
\hline Неспецифическая микробная флора & 30 & 12 \\
\hline Mусорlasma genitalium & - & 6 \\
\hline Mycoplasma homini & - & 7 \\
\hline Ureaplasma urealyticum & - & 11 \\
\hline Chlamydia trachomatis & - & 6 \\
\hline Candida spp. & 7 & \\
\hline
\end{tabular}

На терапевтическом этапе исследования, на фоне специализированной урологической физиотерапии, был проведен дифференцированный курс этиотропной терапии.

В Г1: пероральное назначения препарата «Цефпотек» (Нобель) по 1 таблетке (200 mg) 2 раза в сутки в рамках курса продолжительностью 14 суток с возможностью продления курса до 28 суток.

В Г2: пероральное назначения препарата «Клабел» по 1 таблетке $(500 \mathrm{mg}) 2$ раза в сутки в рамках курса продолжительностью 14 суток.

Пациенты с признаками ассоциированного c Candida spp. поражения дистальных отделов урогенитального тракта (баланопостит) или при подтверждении наличия в эякуляте мицелия инфекционных агентов данной группы, получали дополнительно препарат «Фунит» перорально по 1 капсуле (100 mg) в сутки в рамках курса продолжительностью 14 суток; при установлении ассоциированной с возбудителем патологии у партнера - «Фунит» перорально 2 капсулы (200 mg) 2 раза в сутки однократно в первый день терапии. Итраконазол (Фунит) действует на типичную и атипичную кандиду, которая часто является спутником хронического воспалительного процесса.

На обсервационном этапе исследования был проведен анализ клинической и лабораторной эффективности терапевтических моделей в группах.

Критериями клинического выздоровления были установлены: 
- ликвидация региональных болевых синдромов (тазового, поясничного, пахового, ректального, локально-абдоминального);

- ликвидация дизурии и никтурии;

- снижение выраженности общих симптомов (слабость, головные боли и пр.).

Критериями лабораторного выздоровления были установлены:

- отсутствие возбудителя при бактериологическом исследовании эякулята;

- отсутствие маркеров воспаления при микроскопическом исследовании эякулята (значимое наличие лейкоцитов в поле зрения);
- отсутствие маркеров воспаления при рутинном анализе мочи (значимая лейкоцитурия);

- условная нормализация показателей анализа крови (лейкоцитарная формула, С-реактивный белок, СОЭ);

- условная нормализация показателей сонографического исследования предстательной железы;

- отрицательный результат при повторном проведении ПЦР.

Таким образом, результаты терапевтического этапа исследования терапевтических моделей представлены в табл. 2.

Таблица 2

Соответствие критериям клинического и лабораторного выздоровления в группах по окончанию терапевтического этапа исследования

\begin{tabular}{|c|c|c|}
\hline Критерий & $\begin{array}{c}\Gamma 1 \\
(\mathrm{~N}=30)\end{array}$ & $\begin{array}{c}\Gamma 2 \\
(\mathrm{~N}=30)\end{array}$ \\
\hline \multicolumn{3}{|l|}{ Критерии клинического выздоровления } \\
\hline ликвидация региональных болевых синдромов & 29 & 23 \\
\hline ликвидация дизурии и никтурии & 29 & 26 \\
\hline снижение выраженности общих симптомов & 21 & 25 \\
\hline \multicolumn{3}{|l|}{ Критерии лабораторного выздоровления } \\
\hline отсутствие возбудителя при исследовании эякулята & 28 & 24 \\
\hline отсутствие маркеров воспаления при исследовании эякулята & 25 & 24 \\
\hline отсутствие маркеров воспаления при рутинном анализе мочи & 30 & 30 \\
\hline условная нормализация показателей анализа крови & 30 & 30 \\
\hline условная нормализация показателей сонографии & 22 & 17 \\
\hline отрицательный результат при повторном проведении ПЦР & - & 26 \\
\hline
\end{tabular}

Далее приведен анализ эффективности терапевтических моделей.

В Г1 клиническое выздоровление по критериям ликвидация регионарных болевых синдромов, дизурии и никтурии было достигнуто у 29 пациентов (96,6\% группы). Общие симптомы, ассоциированные с перенесенной интоксикацией и прочими факторами, психологическим стрессом и прочими) были нормализованы у 21 пациента (80\% группы).

Лабораторное выздоровление по основным критериям: отсутствие возбудителя при исследовании эякулята было достигнуто у 28 (93,3\%), отсутствие маркеров воспаления при исследовании эякулята было достигнуто у 25 (83,3\%) пациентов. По косвенным критериям (отсутствие маркеров воспаления при рутинном анализе мочи, условная нормализация показателей анализа крови) - у всех пациентов группы. Условная нормализация показателей сонографического исследования предстательной железы имела место у 22 пациентов (73,3\% группы), что может быть объяснено невозможностью четкого разграничения пропор- 
ции остаточных явлений инфекционного воздействия и фонового патологического процесса данным методом. Отрицательная реакция ПЦР в данной группе считалась не валидной в виду неспецифического характера инфекционного агента.

В Г2 клиническое выздоровление по субъективным критериям (ликвидация регионарных болевых синдромов было достигнуто у 23 (76,6\%), дизурии и никтурии было достигнуто у 26 (86,6\%) пациентов. Общие симптомы были нормализованы у 25 пациентов (83,3\% группы). Больший эффект в Г2 по сравнению с Г1 в отношении последнего показателя объясняется меньшим инициальным влиянием специфических возбудителей на общее состояние.

Лабораторное выздоровление по основным критериям: отсутствие возбудителя при исследовании эякулята было достигнуто у 24 (80,0\%), отсутствие маркеров воспаления при исследовании эякулята у 24 (80,0\%) пациентов. По косвенным критериям (отсутствие маркеров воспаления при рутинном анализе мочи, условная нормализация показателей анализа крови), так же, как и в Г1 - у всех пациентов группы. Условная нормализация показателей сонографического исследования предстательной железы имела место у 17 пациентов (56,6\% группы), что может быть объяснено более стойким характером воздействия специфических возбудителей на морфологические структуры простаты. Отрицательная реакция ПЦР была отмечена у 26 пациентов (86,6\% группы), что является информативным показателем в отношении специфических инфекционных агентов.

Таким образом, общая эффективность терапевтических моделей в Г1 рассматривается в диапазоне от 83,3\% до 96,6\%, в Г2 - от $80,0 \%$ до 86,6\% (вне зависимости от особенностей сочетаний специфической микст-инфекции).

Выводы. На основании анализа эффективности фармакологических препаратов «Цефпотек» и «Клабел» в терапии хронического воспаления предстатель- ной железы в стадии выраженного обострения, вызванного неспецифическими инфекционными агентами и инфекциями mycoplasma genitalium, mycoplasma hominis, ureaplasma urealyticum, и chlamydia trachomatis, были установлены показатели клинического и лабораторного выздоровления в контингенте исследования. Для терапии хронического простатита, вызванного внутриклеточными возбудителями, был выбран кларитромицин фармацевтической компании Нобель «Клабел», т.к. он сочетает в себе высокое качество и оптимальную цену. Кларитромицин активно действует на типичные и атипичные возбудители, а также разрушат матрикс бактериальных биопленок, что способствует проникновению кларитромицина в бактерии и позволяет ему активно работать при хронических процессах.

При терапии хронического воспаления предстательной железы в стадии выраженного обострения, вызванного неспецифическими инфекционными агентами с использованием перорального назначения препарата «Цефпотек» (Нобель) по 1 таблетке (200 mg) 2 раза в сутки в рамках курса продолжительностью 14 суток с возможностью продления курса до 28 суток, полная эффективность была достигнута в диапазоне от 83,3\% до 96,6\% наблюдений. Хотелось бы отметить хорошую переносимость терапии Цефпотеком, с его минимальным влиянием на микрофлору кишечника, благодаря технологии «prodrug».

При терапии хронического воспаления предстательной железы в стадии выраженного обострения, вызванного инфекционными агентами группы mycoplasma и chlamydia с использованием перорального назначения препарата «Клабел» (кларитромицин) по 1 таблетке (500 mg) 2 раза в сутки в рамках курса продолжительностью 14 суток, полная эффективность была достигнута в диапазоне от 80,0\% до 86,6\% наблюдений (вне зависимости от особенностей сочетаний специфической микст-инфекции). 


\section{СПИСОК ЛИТЕРАТУРЫ}

1. Bisschop M.P. et al. Co-treatment of the male partner in vaginal candidosis: a doble-blind randomized control study. British Jornal of Obstetrics and Gynaecology 1986, 93 (1): 79-81.

2. Coker TJ, Dierfeldt DM. Acute Bacterial Prostatitis: Diagnosis and Management. Am Fam Physician. 2016 Jan 15;93(2):114-20.

3. Gill BC, Shoskes DA. Bacterial prostatitis. Curr Opin Infect Dis. 2016 Feb;29(1):86-91.

4. Krieger JN, Ross S0, Limaye AP, Riley DE. Inconsistent localization of gram-positive bacteria to prostate-specific specimens from patients with chronic prostatitis. Urology. 2005 0ct. 66 (4):721-5.

5. Magri V, Perletti G, Montanari E, Marras E, Chiaffarino F, Parazzini F. Chronic prostatitis and erectile dysfunction: results from a cross-sectional study. Arch Ital Urol Androl. 2008 Dec. 80(4):172-5.

6. Pontari MA. Etiology of chronic prostatitis/chronic pelvic pain syndrome: psychoimmunoneurendocrine dysfunction (PINE syndrome) or just a really bad infection?. World J Urol. 2013 Apr 12.

7. Wiygul RD. Prostatitis: epidemiology of inflammation. Curr Urol Rep. 2005 Jul. 6(4):282-9.

8. Горпинченко І. І., Литвинець Є. А., Сандурський 0. П. та ін. Діагностика хронічного простатиту: сучасні реалії та проблеми // Здоровье мужчины. 2014. № 1. С. 105-110.

\section{PEЗЮME}

\section{АНАЛІЗ ЕФЕКТИВНОСТІ ПРЕПАРАТІВ «ЦЕФПОТЕК» ТА «КЛАБЕЛ» У ЛІКУВАННІ СПЕЦИФІЧНОГО ТА НЕСПЕЦИФІЧНОГО ХРОНІЧНОГО ПРОСТАТИТУ}

\section{Ю. І. Засєда, Р.І.Солом'яний, Ф.Б. Шихалієв}

\begin{abstract}
Мета дослідження: встановлення ефективності препаратів «Цефпотек» (цефподоксим) $і$ «Клабел» (кларитроміцин) в терапії хронічного запалення передміхурової залози в стадії вираженого загострення, викликаного неспецифічними інфекційними агентами i інфекціями групи тусорlasma i chlamydia.
\end{abstract}

матеріали та методи. Дослідження проведено в проспективному дизайні на паралельних групах. Контингент дослідження склали 60 пацієнтів ТОВ "Клініка «Мужское Здоровье», які страждають на хронічний простатит, в стадії вираженого загострення. В якості методів дослідження були використані: сонографічне дослідження передміхурової залози, бактеріологічний посів еякуляту, аналіз секрету простати $i$ ПЛР-діагностика специфічних інфекцій.

Результати дослідження. Проведено диференційований курс етіотропної терапії. При неспецифічному простатиті: пероральне призначення препарату «Цефnотек» по 1 таблетиі (200 mg) 2 рази на добу в рамках курсу тривалістю 14 діб з можливістю продовження курсу до 28 діб. При специфічному простаmumi: пероральне призначення препарату «Клабел» (кларитроміцин) по 1 таблетиі (500 mg) 2 рази на добу в рамках курсу тривалістю 14 діб.

Висновки. При терапії хронічного запалення передміхурової залози в стадії вираженого загострення, викликаного неспецифічними інфекційними агентами з використанням перорального призначення препарату «Цефпотек», повна ефективність була досягнута в діапазоні від 83,3\% до 96,6\% спостережень. При терапії хронічного запалення передміхурової залози в стадії вираженого загострення, викликаного інфекційними агентами групи mycoplasma i chlamydia з використанням перорального призначення препарату «Клабел», повна ефективність була досягнута в діапазоні від 80,0\% до 86,6\% спостережень (незалежно від особливостей сполучень специфічної мікст-інфекції).

Ключові слова: простатит, мікст-інфекція, антибіотикотерапія, мікоплазма, хламідія.

\section{SUMMARY}

\section{THE ANALYSIS OF EFFICACY OF "CEFPOTEC" AND "CLABEL" PREPARATIONS IN TREATMENT OF SPECIFIC AND NONSPECIFIC PROSTATITIS}

Yu. I. Zasieda, R. I. Solomianyi, F. B. Shykhaliiev

Objective: to establish the effectiveness of Cefpotek (cefpodoxime) and Clabel (clarithromycin) drugs in the treatment of chronic prostate inflammation in the stage of pronounced exacerbation caused by nonspecific infectious agents and infections of the mycoplasma and chlamydia groups.

Materials and methods. The study was conducted in a prospective design on parallel groups. The study contingent consisted of 60 patients of the "Men's Health Clinic", suffering from chronic prostatitis in state of pronounced exacerbation. The following research methods were used: sonographic examination of the prostate gland, bacteriological examination of the ejaculate, analysis of ejaculate and $P C R$ diagnostics of specific infections.

The results of the study. A differentiated course of etiotropic therapy was carried out. In case of non-specific prostatitis: oral administration of the drug "Cefpotek" (cefpodoxim) 1 tablet $(200 \mathrm{mg}) 2$ times a day for a course of 14 days with the possibility of extending the course to 28 days. With specific prostatitis: oral administration of the drug "Clabel" 
(clarithromycin) 1 tablet $(500 \mathrm{mg}) 2$ times a day for a course of 14 days.

Conclusions. In the treatment of chronic inflammation of the prostate gland in the stage of pronounced exacerbation caused by nonspecific infectious agents using oral administration of the drug "Cefpotek", the full effectiveness was achieved in range from $83.3 \%$ to $96.6 \%$ of observations. In the treatment of chronic inflammation of the prostate gland in the stage of pronounced exacerbation caused by infectious agents of the mycoplasma and chlamydia groups using oral administration of the drug "Clabel", the full effectiveness was achieved in the range from $80.0 \%$ to $86.6 \%$ of observations (regardless of features of combinations of specific mixed infections).

Key words: prostatitis, mixed infection, antibiotic therapy, mycoplasma, chlamydia.

\section{АВТОРСКАЯ СПРАВКА}

- Заседа Юрий Игоревич, д. м. н. Главный врач клиники «Мужское Здоровье» г. Киев. Телефон: +380976500444. E-mail: zasieda@gmail.com.

- Засєда Юрій Ігорович, д. м. н. Головний лікар клініки «Мужское Здоровье» м. Київ. Телефон: +380976500444. E-mail: zasieda@gmail.com.

- Zaseda Yuri Igorevich. MD, Urologyst, Andrologyst, PhD, Doctor of Science, CM0 of Men's Health Clinic, Kiev. Contact number: +380976500444. E-mail: zasieda@gmail.com.

Стаття надійшла до редакції 30.12.2018

У разі виникнення питань до автора статті, звертайтесь до редакції журналу сеотеnshealth@gтаil.com 